\title{
A Fair Accord: Cradle to Cradle as a Design Theory Measured against John Rawls' Theory of Justice and Immanuel Kant's Categorical Imperative
}

\section{Jacob Voorthuis * and Cyrille Gijbels}

Eindhoven University of Technology, Den Dolech 2, P.O. Box 513, 5600 MB Eindhoven, The

Netherlands; E-Mail: C.E.H.Gijbels@student.tue.nl

* Author to whom correspondence should be addressed; E-Mail: J.C.T.Voorthuis@ @wk.tue.nl; Tel.: +31-40-247-9111; Fax: +31-40-245-6087.

Received: 7 December 2009 / Accepted: 19 January 2010 / Published: 25 January 2010

\begin{abstract}
This essay explores a specific aspect of the role of attitude in design. The design of the built environment requires us constantly to make aesthetic and ethical judgments; every design decision has to be satisfactorily justified. Surprisingly perhaps, this requires a clear concept of justice against which a design can be grounded. Aesthetic concerns about quality spill into ethical concerns about the rightness of a decision and vice versa. This essay discusses a simple but crucial question: if a designer is aware of Cradle to Cradle as a theory of design but fails to act according to its principles, is it then possible to justify the resultant design? In other words, is Cradle to Cradle as a design theory that most rare of transcendental notions: a Categorical Imperative? Why might it be useful to describe it as such? Does the fact that we do not yet know how to redesign most products and processes according to its principles disqualify the theory? Does a dismissal of the Cradle to Cradle theory inevitably lead to an unfair society? These are serious questions, with interesting answers and far reaching implications for the way we think about design. First we shall explain what Cradle to Cradle means and how it distinguishes itself from other theories of sustainability. Then we shall put that explanation in the context of two ethical theories, first of all John Rawls' Theory of Justice and second Immanuel Kant's concept of the Categorical Imperative. After that we shall note a few problems concerning Cradle to Cradle design theory and put those into perspective. This will lead to an important attitudinal conclusion, namely that Cradle to Cradle can legitimately be described as one of those extremely rare cases which deserves universal applicability. We will offer a two-pronged strategy as to how to proceed.
\end{abstract}


Keywords: Cradle to Cradle; Categorical Imperative; Justice as Fairness

\section{Introduction: Cradle to Cradle}

Here is our thesis: As long as architects and developers remain ignorant of a design theory as compelling as Cradle to Cradle, our good intentions with regard to the environment and the development of a sustainable building culture will come to nothing: Less bad, which is the ethos of most current thinking with regard to sustainability, is not by definition good. In order to understand such a thesis we need to familiarize ourselves with Cradle to Cradle as a theory of design.

Chemist Michael Braungart and architect William McDonough introduced their Cradle to Cradle theory in 2002 with the book 'Cradle to Cradle: Remaking the Way We Make Things' [1]. They saw contemporary approaches to sustainability as attempts confined to limiting the negative effects of the industrial revolution, as ways to optimize an essentially bad system. By trying to deal exclusively with the consequences of a system (end-of-pipe) a real solution would, they argued, continue to elude us. For a real solution they felt it was essential to look at the whole causal network of the problem that our system of production and consumption poses. The mission of Cradle to Cradle as a design theory is to generate an innovative attitude to design leading to a complete overhaul of our approach to our relationship with the environment.

This, they argue, requires the complete elimination of waste. Not so much by producing less of it, but by producing a waste that does not have to be seen as waste but which becomes a food (feedstock) for some other part of the ecosystem. Nature constitutes an aggregate of systems which are inherently Cradle to Cradle. A natural approach to design would be one which would conform to this paradigm. Exemplary of this naturalness are ants. The combined biomass of ants is larger than that of the human population of the world and yet they form a good example of a population which, despite its density and productivity, causes no irreversible problem for the rest of the world. The reason for this is that everything they produce and use is put into circulation according to the principles of Cradle to Cradle. According to Michael Braungart we are, unlike ants, 'not too many, just stupid' [1].

There are a number of ways of looking at waste. The linear concept of design, also called Cradle to Grave-results in physical waste; a final product that is no longer useful and which is therefore discarded and may well affect our environment adversely in some way. In trying to eliminate waste in this sense Cradle to Cradle would require us to redesign products and processes completely, so that materials and processes can be introduced which at the end of their useful life as that product, simply offer themselves as raw material (technical nutrient) for another new product in the technical cycle or as a biological nutrient for the biological cycle. Waste becomes food. An illustration of these two cycles is provided in Figure 1.

But waste is more than just a physical product. Another form of waste is the tabula rasa resulting from our neglect of the historical and cultural layering of an environment, whereby relationships between people and their environment are disturbed and thrown out of balance. During the development of an urban plan according Cradle to Cradle principles, it would essential to take account of the cultural and historical layering of a city in the design; everything that is present needs to be 
taken into account as a point of departure for future developments. Waste in that sense is the negligent and nonchalant treatment of existing qualities which constitute food for the development of a culture. By being destroyed, far more is destroyed than just the environment; our sense of ourselves is destroyed with it.

Figure 1. Biological and technical cycles [2].

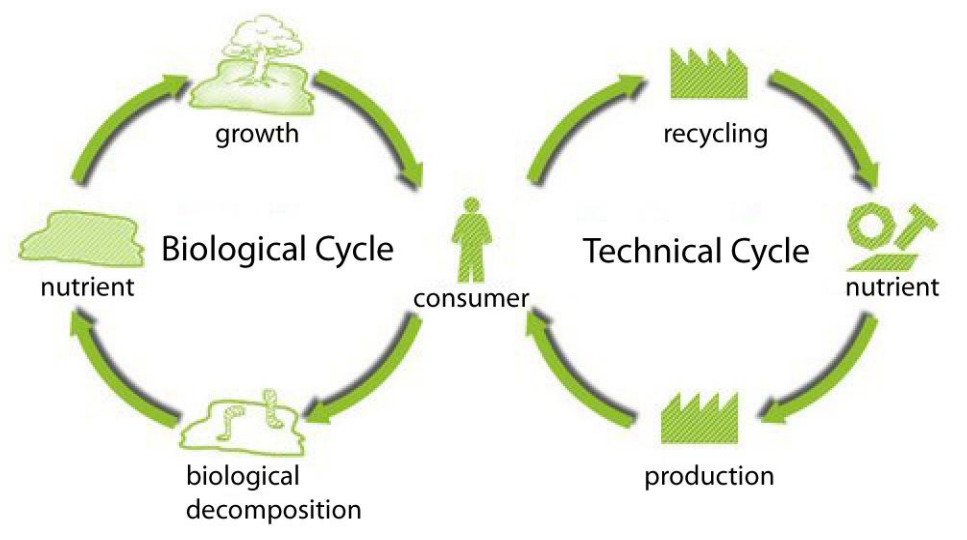

A third form of waste concerns the 'wasting' of our biodiversity as a by-product of agriculture's self-defeating attempt to maximize efficiency through the intense development of mono-cultured landscapes. In order to remain commercially viable, these relatively simplistic man-made eco-systems are kept artificially stable through a process of chemical inflation. The seasonal need to use evermore powerful chemicals to eliminate the increasingly resistant natural enemies of the flora and fauna cultivated can at best achieve a short-lived stability. These immunized landscapes, unlike their natural and complex counterparts, cannot survive by themselves. Cradle to Cradle thinking puts a concern for biodiversity at the very core of its theory. Local extant qualities with reference to flora and fauna form the point of departure for any future intervention. The adage think global act local forms the very basis of Cradle to Cradle thinking.

A fourth aspect of waste is the problem of hidden additives. At this moment most products should really be described as 'products + '. A product + is a product that contains hidden additives which may be harmful when released into the environment. Cuddly toys, wallpaper and carpets are not free of plus additives. These constitute an obvious problem for recycling. Recycling is one of the fundamental aspects of contemporary approaches to sustainability, however recycling such materials results in the additives being released into the environment in a way for which they were not originally designed. This makes their effect hard to control. To paraphrase Michael Braungart: 'People may feel they are making an ecologically sound choice by buying and wearing clothing made of fibres from recycled plastic bottles. But the fibres from plastic bottles contain toxins such as antimony, catalytic residues, ultraviolet stabilizers, plasticizers, and antioxidants, which were never designed to lie next to human skin' [1].

A related problem is the issue of down-cycling materials. Recycling would be a good thing if, and only if the material in question could be reintegrated into circulation at the qualitative level it had at the start of its useful life. In current recycling processes, however the material being recycled is subject to degradation so that any form of recycling also automatically implies a down-cycling. Aluminium is 
a good example of a material which is constantly being down-cycled. The typical soft drink can consists of two kinds of aluminium: the walls are composed of aluminium and a manganese alloy containing some magnesium, coatings and paint, while the harder top is an aluminium magnesium alloy. In conventional recycling these materials are melted together, resulting in a weaker-and hence less useful-product [1].

By designing products using pure materials that can simply revert to being a simple raw material at the end of their useful life, we set up mono-material circulation streams. Even when a material is not certified as fully Cradle to Cradle, it is possible, and indeed important to close the cycle in such a way that the material cannot get mixed up with other materials or leak away into the environment. As soon as the requisite technology is sufficiently developed to make isolation technically and economically feasible so that the material can be improved before it is brought back into circulation, we can speak of up-cycling.

Current approaches to sustainability are primarily geared to optimizing existing products and processes. That is, they are made more efficient without taking account of the fundamental need for an attitudinal paradigm shift. The optimisation of existing methods of production and consumption merely results in things being less bad rather than positively good. Braungart and McDonough describe this approach as eco-efficient-doing things we were already doing, but doing them better. Cradle to Cradle by contrast is the attempt to become eco-effective. That is, doing the right thing from the start. That is the difference between conventional sustainability thinking and the Cradle to Cradle theory. By eliminating waste in all of its manifestations, a regulative system is introduced for society which is self sustaining.

There is another aspect that makes the Cradle to Cradle theory of design stand out and that is its insistence that all design decisions be tested against three concepts: Equity, Ecology and Economy. The first, Equity ensures that everything in an eco-system is treated fairly. This means for example that production must not proceed at the expense of human or indeed animal rights. Ecology describes the foundational image of the world we are pursuing: i.e., a world where waste is eliminated. The slogan waste $=$ food and the need to pursue the up-cycling of materials would fit this image. But, however promising the first two concepts of Equity and Ecology are, they need to be made practicable and feasible in the world we live in at this moment in order to save them from popular and political dismissal as mere fantasies. For this reason cost-effectiveness, competitiveness and profitability are paramount conditions for the success of the Cradle to Cradle theory of design. The idea of Economy thus takes up its place as the third term in a stable triad. Only when each of the three demands is tested against each of the other in making a design decision can we truly speak of a Cradle to Cradle design. In extreme terms this means that a product is only Cradle to Cradle if it is completely reusable that is, that it does not produce any kind of waste; that it is at the same time competitively priced and profitable, without having been produced using unfair means such as cheap labour or any form of enslavement. If any one of these criteria is not fulfilled, a design cannot strictly qualify as Cradle to Cradle. This presents quite a challenge; at the same time it is this moral dimension that suggests it might be profitable to measure the theory against two seminal ethical theories in order to attempt to get clear what our attitude to this theory of design should be. First of all we shall measure Cradle to Cradle thinking against John Rawls' theory of Justice as Fairness, and secondly we shall see how far we can 
go by holding it up against Immanuel Kant's extremely problematic but highly compelling Categorical Imperative.

\section{Fair Justice}

It should be clear by now that the environmental impact of a design has to be taken into account during the entire design process. Designers cannot ignore such issues when attempting to ground and justify their design decisions. Design is about justification and judgment and to be able to judge and justify our decisions we need to have a well-developed and well practised attitude to the world we are designing for. As such a concept of justice is a prerequisite for any designer. Theories of justice cover that aspect of our being in the world in which we are forced to take a stand on our being there, with which is meant our participation in a world in which we are all looking to survive the ride while making our stay here as comfortable and fulfilling as possible. To accomplish this we interfere with each other and with our environment. We cannot help doing so. It is the basis of our socialisation as organisms. A concept of justice measures our engagement with the world and our use of it in order to maintain ourselves and our environment as a whole. Too often this aspect of design theory is ignored in favour of the more fragmented concerns of form. This is a shame, as a good theory of justice can influence the whole approach to design in all its aspects. This is best illustrated with reference to John Rawls' thinking.

One of the most convincing and workable theories of justice is that of John Rawls, as worked out in his book A Theory of Justice [3]. It concerns a theory that he summarises with the slogan Justice as Fairness. When Plato's Socrates discussed the concept of justice, he did so by designing what he considered a just society. That design became known as The Republic as featured in Plato's Politeia. It was a concrete example of a carefully organised and meticulously structured social space. The interesting thing is that The Republic was arrived at through discourse in the form of a Socratic conversation. The problem with this utopia avant la lettre however, was its concrete nature; it was static, immobile and inflexible, it could not adjust; it could not develop and differentiate, evolve, and crucially, it had the luxury of being able to take the stability of the environment for granted. It was doomed to fail, as are all utopias which rely on the concrete and the over-determined. Man is, as Nietzsche was fond to point out, the undetermined animal: we have the ability to overcome our limitations, even those imposed by evolution.

When John Rawls decided to design a just society he too put the notion of a conversation at the centre of his endeavour. Through his design conversation, of which we shall study the game rules in greater detail further down, he arrived not at a concrete description of a society like The Republic, but at a very simple and manageable set of game-rules or principles to apply at every step of the way in the design process. It concerned a set of rules moreover, that could be used to test and measure any development within that society, including environmental concerns. These rules he summarised with the slogan Justice as Fairness.

With the word fairness Rawls engages the traditional discipline of aesthetics by placing one of the conventional and at the same time most effective and desirable qualities of being human at the very centre of his concerns. Fairness refers to rightfulness and legitimacy, reasonableness and even equanimity. Fairness makes a generous approach to self-maintenance possible. When goods are fairly 
distributed there is no edge to that distribution, no reason for jealousy, revenge or bitterness. Fairness is of course a bodily determined emotion, a situated feeling determining the relationship between the body and some aspect of its environment, whether that is another person, thing or event [4]. Fairness is also a species of beauty; it is used to denote good weather and attractive ladies. These connotations cannot be simply dismissed as irrelevant. They mesh. To separate them is to perform semantic violence and to remove the climate a word brings to bear on a subject. Fairness is a generic word that connotes the mood of our engagement with the world, a mood of the gentlemanly, the considerate, the chivalrous suffused with an openly self-interested generosity toward the other, a generosity without undue altruism. Fairness is where self-interest and the greater good affirm each other. Fair behaviour is, in a sense, beautiful behaviour; it shows decorum because it serves us-as-part-of-a-whole, engaging that sense of accord that lies at the foundation of our participation in a world. When things are fair we fit comfortably into the bigger picture. Everything has its place. It is this aspect of fairness that brings Cradle to Cradle in to the picture: the idea of being a part of a whole with acknowledged needs and desires. Cradle to Cradle thinking is fair because it is not restrictive with regard to consumption, in fact it positively promotes consumption; it restricts us only with regard to the design and manufacture of products for consumption, it demands that we see ourselves as part of a larger picture into which we can fit quite comfortably as long as we do the right thing. The slogan waste = food, is fair. In other words all products should be so designed as to encourage use and re-use through up-cycling and proper recycling. It does not say we should use less, it says we should use lots of things that can in time produce a lot more things. This carefully nuanced restriction in Cradle to Cradle thinking is important for the argument as it engages two of Rawls' central game-rules for a fair society.

Rawls argued that a group of people discussing the design of a just society would, human beings being what they are, inevitably arrive at a conception of society where two ground rules would be agreed upon unanimously, without exception. The first is the principle of liberty, which constitutes a contract agreement that each person in a just and fair society should be free to pursue their own good. The priority of this principle over all others implies that one person's good can never be considered a good if it constitutes an obstacle to someone else's pursuit of their good, even if that someone else comes a generation or two later.

The second principle is the so-called difference principle. This says that inequality in a society is just and fair if, and only if, any action to promote the good of one person also promotes the good of the others. More important than absolute equality then, is a well-grounded and situationally determined feeling of fairness. This makes possible a far more plausible distribution of goods than strict equality ever could. Put in terms of the word economy just employed with reference to Cradle to Cradle, we can say that profitability is not an evil in itself; it is evil only if an action or measure profits one person at the expense of another. These theoretically simple rules are to be applied in strict order of preference to every step of the design process: Liberty comes first and has priority over any and every other game rule we might devise for our design thinking, and the difference principle comes second. This order is paramount to avoid, among other things, the utilitarian problem where the possibility of harmful compromise lies at the surface of the theory allowing the institution of a dictatorship of the majority.

Cradle to Cradle thinking answers both the liberty principle as well as the principle of difference with ease. Not only does it provide a blueprint for the pursuit of cooperative and non destructive 
freedom but it creates an environment where the good of one is not the bad of another. Cradle to Cradle as a theoretical stand would appear to increase the goods to global society as a whole and make the distribution of those good less problematic as its waste becomes food for some other partner in the chain, and allow us to pursue a freedom conditioned only by the demand that it does not restrict the freedom of others. Cradle to Cradle thinking appears to be one of the extremely rare instances where this is at least theoretically possible.

Rawls arrives at this conception of Justice as Fairness through the use of two philosophical instruments, namely the reflective equilibrium and the veil of ignorance. These instruments are in fact game rules for what we might call a design conversation: a discussion a group of people will embark on to arrive at the design of, say, a car, a complex building, or indeed a just society. The veil of ignorance is an instrument whereby the participants have their humanity left intact but their situatedness removed for the purposes of that design conversation. This has the effect that they do not have to imagine themselves wonderful people, benevolent saints or altruistic martyrs while participating in the design process; they have to imagine themselves, quite simply, as ordinary self-interested people, much as they no doubt are. At the same time they are no ordinary, ordinary people, for although their humanness is left intact, they have been systematically disentangled and immunised from any conception of their concrete situation. This carries the advantage that participants in the design process of, in his case a just society, are not to know whether they are white or black, male or female, rich or poor, alive now or alive in three generations time. This unsituatedness stops them making choices from the perspective of their particular situation, shaped by short term concerns and narrowly conceived desires. Their perspective shifts to a specific but unsituated view without cancelling out the self and its interest. The reflective equilibrium stands for the moment at which the conversation between these unsituated people arrives at a plateau of conditional consensus about the design of their just society.

Our current global concerns can no longer be involved in the design of a just society without taking into account the environment as a whole. The interesting thing is that Rawls' discursive game for the design of a just society allows people to think clearly about social and environmental perspectives of justice. For the design of our environment we need to take Rawls' game rules for his conversation between unsituated people to a new level. To do this we need to strip our situatedness even further. Not only are we not to know that we are white or black, female or male, young or old, living now or in the future, but in the design for the total environment we need to take into account the desires of other living creatures in whose cycles we and our designed environment interferes and thus forms a part. Human beings now have to learn to think through the idea of being part of an even greater whole than society, and the veil of ignorance is a powerful instrument to help there. Cradle to Cradle thinking with its wish to transform waste into food, is a concrete instance of such widely conceived discourse which consciously takes account of the paradoxical knowledge that man is in a position to destroy himself through his use of the environment to maintain himself. By taking on the design of a product as large as an environment all design as an active part in that environment has to be tested against what we might call the Rawls' constant: the game rules of Liberty and Fairness and our knowledge of Cradle to Cradle. Rawls provides a compelling philosophical basis for theories such as Cradle to Cradle, but also for a transcendent humanism, whereby we acknowledge that to be human is to be an integral part of a full world. Cradle to Cradle, we believe, is an exemplary candidate for the promotion of the kind of 
fair society as outlined by John Rawls. It not only does not contradict the two principles of freedom and fairness, it explicitly affirms them and even shows us a concrete instance of how to interpret such a freedom and making possible the conditions for a fair distribution of goods, theoretically that is.

\section{Cradle to Cradle as a Categorical Imperative}

Before we start worrying about that word theoretical, we would like to ask whether we can take it a step further. Immanuel Kant's notion of the Categorical Imperative is one of the foundation stones of modern ethical theory. It was put forward in 1785 in his Groundwork of the Metaphysic of Morals in which he attempted to establish a moral framework for action that went beyond experience. This is not the place to discuss the Categorical Imperative exhaustively, so we shall simply summarize the three main formulations of this essentially biblical adage: do not unto others what you would not have done unto yourself. Kant's formulation is as follows [5]:

1. Act only according to that maxim whereby you can and at the same time will that it should become a universal law.

2. Act in such a way that you treat humanity, whether in your own person or in the person of any other, always at the same time as an end and never merely as a means to an end.

3. ...every rational being must so act as if he were through his maxim always a legislating member in the universal kingdom of ends.

The questions we are considering are whether these maxims are exemplified by Cradle to Cradle thinking; whether this theory is worthy of such unconditional universality, whether unconditional universality is a good thing and how all these considerations might affect the activity of design itself. As we have already argued, Cradle to Cradle can, because of its elimination of waste, with some legitimacy lay claim to the status of being natural in the sense that it tries to reintroduce, for modern society, a way of producing and consuming goods that allows full circulation in nature by the elimination of waste with respect to both the biosphere and the technosphere, so that both can coexist comfortably without adversely affecting each other. However, the Categorical Imperative is a problematic moral guide as it explicitly puts law before experience. This means that it can quickly lead to absurd behaviour if one is not careful as to what kind of actions one allows to fall under its authority. Kant got dangerously near such a situation by declaring the act of lying subject to a Categorical Imperative: he argued that one should never lie. However, the experience of daily life in our present culture would be made very difficult indeed without at least the occasional selective presentation of truths. Our little vanities cannot bear too much truth. The Categorical Imperative covers actions which are right in any situation, performed by any member of the universe of conscious beings endowed with a free will. If we were to use the veil of ignorance to help us discover valid categorical imperatives, there would be very few practices or principles that could be given that kind of status without leading to absurd or hurtful behaviour in our present society.

To put law before experience is extremely risky. It is our experience of the world that constantly allows us to correct behaviour relative to concrete situations. The reflective power that experience provides, not only gave us our industrial revolution but is also responsible for bringing us back to our senses now that things have gone too far. Furthermore experience has given Braungart and 
McDonough the instruments to formulate their design theory. By making Cradle to Cradle into universal law independent of experience we must ask ourselves whether we are not relinquishing our responsibility for our actions by abandoning the theory to something equivalent to divine status. This would invite all sorts of forces to tend to the theory, some of which would not be welcome from a scientific perspective. A theory needs to be kept in shape on the basis of our experience with it. Imagine such a theory being made subject to catechism and being transformed into a set of dead rituals performed without due critical attention. What exactly then would be the advantage of having law grounded on something beyond or prior to experience?

Perhaps we are not looking at this thing in the right way. Does a transcendent notion necessarily go beyond experience? Referring to Kant's three maxims, a Categorical Imperative has to be grounded upon an accord between any action and an image of the world that transcends any individual interest. It represents an accord between a part and the conceived whole: with which we mean an instance and that of which it is an instance. If we can define that relationship and describe its terms, we have a way of judging whether a design principle can be afforded such a status and whether it would be useful to give it that status. But we have to be careful as any act that truly obeys the strictures of the Categorical Imperative would then be right, regardless of any resultant consequences. This does not however mean that action subject to a Categorical Imperative does not engage experience; any action is by its very nature part of experience and helps build our frame of reference. However, it cannot be so that experience can ever change the validity of a Categorical Imperative. So what are we really saying? What we think we are saying is that the problem of a Categorical Imperative can be viewed from a more interesting angle than the mere positing of a law beyond experience. We posit the thesis that a Categorical Imperative assumes a complete overlap between experience and law in all possible instances. i.e., a Categorical Imperative could only really deserve such a name when the theoretically possible gap between law and experience, would simply not materialize. A Categorical Imperative is the recognition of an accord between any part and the whole, whereby the conceived relationship between the two has been, as it were, got right. This accord frequently claims the label natural in our design conversations, which possibly explains why no word has been more abused than that one. It is a problematic word, but let it stand. If such an accord has been established, law could never contradict experience. This relieves us of at least one worry with every design decision. We no longer have to worry about whether the design theory itself is a good one; we now merely have to worry about whether our actions conform to its strictures. That is where experience comes in. Experience can help us decide whether we are indeed properly acting within the jurisdiction of the Categorical Imperative or whether an action was off the mark and needs to be adjusted.

To support the idea that Cradle to Cradle deserves the status of a Categorical Imperative we will demonstrate that producing waste is an evil in itself. And this evil has, moreover, to be deducible from the concept of waste. The definition of waste is subject to perspective and geared to our frame of reference. Therefore the real question is whether there is a kind of waste that is never food, and only ever a poison. First of all the evermore powerful chemicals with which modern agriculture tries to eliminate increasingly resistant organisms do not in most cases constitute food for those resistant organisms; such chemicals have merely become ineffective whilst remaining poisonous to almost everything else that comes into contact with them. It is also true that organisms can adapt and learn to feed on poisons. But even if all that can be given, the principle of waste as poison being an evil by 
definition would not change. A poison, as a poison is always bad from the perspective of the living organism that experiences it as such. Secondly, a lot of our waste constitutes waste from one perspective while it is food from another, even though that food sometimes contradicts the principle of equity and fairness, for example, when the waste of the rich forms the food for the poor. Waste which becomes food in this way is currently merely down-cycled food. If it were not, it would not move down the chain. In that case it is an evil by definition as it not only contradicts Rawls' first principle of liberty but also the accord between the part and the whole which forms the aesthetic background to Kant's ethics [6]. Much modern waste falls under this category. Therefore the principles of Cradle to Cradle, which concern the elimination of waste, together form a Categorical Imperative. A fully developed empirical science working on this basis would then have the task to discover which waste is food for which organisms and poisonous for which other organisms. It would try to develop products which turn into food at the right time and do not poison at any time. But any empirical findings of such a science would never alter the principle involved. In this sense it is also useful to talk of Cradle to Cradle as a Categorical Imperative.

\section{Criticism}

That is all very well, but what are we to do here and now? Despite the many promises that are latent in Cradle to Cradle as a theory of design, there are a number of critical responses possible. Most of them concern the problem of arriving at a situation where such a theory could become the norm and be fully implemented. The idea of profitability is all well and good but it is not enough. We are as yet only at the beginning of the attempt to find and think through what Cradle to Cradle might mean for a modern society. Even though the principle may stand right up there with the wish to have a fair and just society, society isn't just and we are making a mess of things. In any case Cradle to Cradle is certainly not the answer to all our problems; before the industrial revolution human society was certainly not just, even though it was, more or less, fully Cradle to Cradle. It will take a very long time to re-establish such a state of affairs. Until such a time we will be generating products + and we will increase that production in order to keep up with the growth of the world's population. We will continue to put the world under pressure for more space and more productivity. Many materials, even if they are Cradle to Cradle, take a long time to complete their 1st lifecycle as products, (especially in buildings) before being rereleased as raw material. We will therefore continue to need virgin materials in order to keep up production. There is a long way to go, before we can fully apply Cradle to Cradle thinking.

\section{How to Proceed: A Two-Pronged Strategy}

If Cradle to Cradle cannot be realized in the short term, what do we do? Do we just give up on such a compelling idea? No. There is a possible two pronged strategy. The first concerns the full implementation of other forms of sustainability thinking such as Factor Four [7]. Until Cradle to Cradle becomes a fully fledged possibility we shall simply need to change our lifestyle considerably and opt for the important shorter-term gains of sustainable design, so much criticized by Braungart and 
McDonough. Consuming less and more efficiently rather than consuming more without waste will, for a long time determine good and fair behaviour.

In this sense the sustainable business plan [8] of Club Watt is a good example. Club Watt is a dance club in Rotterdam where the architectural design takes impressive, not to say dramatic sustainability ambitions as its point of departure. By redesigning the 'Dance Club' incorporating Smart Technologies, energy consumption is reduced by $30 \%$, water consumption by $50 \%$, waste production by $50 \%, \mathrm{CO}_{2}$ emissions by $30 \%$ while the use of LED lighting will save up to $85 \%$ of energy consumption relative to normal disco lighting. In other words Club Watt is rather a new kind of less is more argument whereby sustainability thinking contributes in no small measure to the novel spatial experience offered during a good night out.

The second prong concerns the way we think through the first in pursuing the long term goal of a modern society adjusted to the idea of cradling. Cradle to Cradle, like Rawls' design for a fair society is not like Socrates' design for a just society: concrete, determined and therefore inflexible and doomed. Instead it is no more than a set of game rules against which any action can be measured and tested if ...you want a fair society. Failure to act according to its tenets is punished only in the widest sense, in that we all suffer from, for example, global climate change. Punishment is not what an imperative is about. The Categorical Imperative, contrary to what most people think, is an appeal to act $a s$ if it is a universal law. The imperative is rather more like a quest conferred to any member of society as a knight in shining armour committed to the image of a fair society; it is a commission to act in a certain way in order to find your way to an open end. The imperative is first and foremost for all of us to look for our responsibilities in our kingdom of ends and legislate accordingly. To be a good king is to serve one's subjects well (in our case the other kings in the rest of the world) by you acting according to the law you yourself deem right and allowing others to do the same. In those few instances where the Categorical Imperative fits, experience and law fuse to such an extent that they can really no longer be told apart, so that not to act according to such principle constitutes the absurd.

Most things do not fall under such wide demands for universality. Most ends are served best by what Kant calls a hypothetical imperative; that is a situated action or set of strategically coordinated actions to serve a specific end. Decisions within conventional sustainability theory would fall under such a heading. At the same time, any design decision arrived at in that way must not be allowed to contradict any valid Categorical Imperative. That would apply to all other sustainable thinking that is not sure of its Cradle to Cradle status. So we now have to test all our design decisions against their hypothetical end and at the same time against the categorical ends as contained in Rawls' Justice as Fairness or, which comes to much the same thing, the three axioms of Cradle to Cradle thinking: Equity, Ecology and Economy. In this way we will be able to move slowly towards a Cradle to Cradle state without throwing the baby out with the bathwater.

That puts quite a strain on our design thinking. Nevertheless it is worth it. The Cradle to Cradle theory of design answers a demand for the restitution of a principle that was part of our natural world before the industrial revolution: waste $=$ food. Cradle to Cradle as a design theory aspires to a universality that is rare, if not unique in design thinking. It sets out a duty that could, without too much of a leap into the unknown be considered universally valid at all times, whatever you are designing, for whatever purpose, in whatever context. The fact that we are at this moment only at the beginning of 
rethinking our design decisions within its framework, to stop doing so and carry on as if nothing has happened would defy sanity.

\section{References and Notes}

1. Braungart, M.; McDonough, W. Cradle to Cradle, Remaking the Way We Make Things; North Point Press: New York, NY, USA, 2002.

2. Tulp, D. Het Cradle to Cradle Concept; Available online: www.danieltulp.nl (accessed on 20 October 2009).

3. Rawls, J. A Theory of Justice; Harvard University Press: Cambridge, UK, 1999.

4. Damasio, A. Looking for Spinoza, Joy, Sorrow and the Feeling Brain; Harcourt: Orlando, FL, USA, 2003.

5. Ellington, J.W. Groundwork of the Metaphysic of Morals, 3rd ed.; Hackett: Indianapolis, IN, USA, 1993.

6. Deleuze, G. Kant's Critical Philosophy; Continuum: London, UK, 2008.

7. von Weizsäcker, E.; Lovins, A.B.; Lovins, L.H. Factor Four: Doubling Wealth-Halving Resource Use; Earthscan Publications: London, UK, 1998.

8. Sustainable Dance Club ${ }^{\mathrm{TM}}$ Home Page. Available online: www.sustainabledanceclub.com (accessed on 20 October 2009).

(C) 2010 by the authors; licensee Molecular Diversity Preservation International, Basel, Switzerland. This article is an open-access article distributed under the terms and conditions of the Creative Commons Attribution license (http://creativecommons.org/licenses/by/3.0/). 